\title{
SERVICE RESEARCH METHODOLOGY: FROM CASE STUDY RESEARCH TO CASE THEORY
}

\section{ABSTRACT}

In this essay Prof. Evert Gummesson, Professor Emeritus at the Stockholm Business School (SBS) and pioneer in the studies in the fields of service, presented the use of case studies in academic research from a European perspective. The article was built through the perspective of service research that evolved to a strategic paradigm more recently. The essay stresses the importance and the proper use of case studies in academic research.

Keywords: Services Research; Case Study Research; Research Methods.

\section{PESQUISA EM SERVIÇOS DE METODOLOGIA: DO ESTUDO DE CASO EM PESQUISA À TEORIA}

\section{RESUMO}

Neste ensaio o Prof. Evert Gummesson, Professor Emérito da Stockholm Business School (SBS) e pioneiro nos estudos do tema de serviços, apresenta o uso de estudos de caso na pesquisa acadêmica a partir de uma perspectiva européia. $\mathrm{O}$ artigo foi construído na pespectiva da pesquisa em serviços que evoluiu para um paradigm estratégico mais recentemente. Este ensaio estressa a importância e o uso apropriado dos estudos de caso na pesquisa acadêmica.

Palavras-chave: Pesquisa em Serviços; Estudos de Caso em Pesquisa; Métodos de Pesquisa. 


\section{INVESTIGACIÓN SERVICIOS METODOLOGÍA: ESTUDIO DE CASO EN BUSCA LA TEORÍA}

\section{RESUMEN}

En este ensayo Prof. Evert Gummesson, Profesor Emérito en la Stockholm Business School y pionero en los estudios en el tema de servicios, presenta el uso de estudios de casos en la investigación académica a partir de una perspectiva europea. El artículo fue construido por una perspectiva de servicio que se desarrolló para un paradigma estratégico mas recientemente. El ensayo estresa la importancia y el uso apropiado de los estudios de caso en la investigación académica.

Palavras-clave: investigación en servicios; estudios de caso en investigación; métodos de investigación.

Note: The article was kindly published by permission: Gummerus, J. \& von Koskull, C., Eds (2015), The Nordic School - Service marketing and management for the future. Helsinki, Finland: Hanken School of Economics.

Evert Gummesson ${ }^{1}$

${ }^{1} \mathrm{PhD}$ (Stockholm University), Dr hc (Hanken), is Professor Emeritus at the Stockholm Business School (SBS), Stockholm University, Sweden. E-mail: eg@sbs.su.se 


\section{INTRODUCTION}

The value and relevance of service research is highly dependent on the methodology-in-use. On an international basis empirical studies with statistical surveys and ensuing factor analysis and hypothesis testing have been done parallel to case study research based on an interpretivist paradigm with qualitative interviews, focus groups and observations. Both approaches have been used to generate theory, primarily theory fragments or mid-range theory but not until recently more inclusive, abstract and general theory, grand theory. The Nordic School has mainly done case study research that is by convention categorized as a qualitative method.

This essay is based on a life long interest in research methodology and knowledge development. It draws on a new book, Innovative Case Study Research in Business and Management (Gummesson, 2015), and presents my efforts to upgrade case study research to case theory and explain why I see it as a powerful and undervalued methodology.

The essay opens with my perception of the emergence of service research. It proceeds with methodology issues: the transition to case theory; the complexity paradigm and interactive research; a definition of knowledge as pragmatic wisdom; the purposes of case theory and theory generation and testing; scientific narratives; context, persona factor and researchscapes; the terrorism of received categories such as quantitative/ qualitative; and brief notes on other parts of case theory. It is followed by a brief where new theory has been generated from the synthesis of a single empirical case and extant literature. The essay ends with a conclusions section.

\section{THE EMERGENCE OF SERVICE RESEARCH}

The interest in service goes back thousands of years and has come and gone among economic philosophers over the past few centuries. This is explained by Lusch and Vargo (2014) in the "Roots and Heritage" chapter in their state of the art book on service-dominant (S-D) logic.

This section is about the recent history of service research and where we are going. It's a selflived history, which has given me privileged access to inside events. We may think that history is easy to report - it has already happened, hasn't it? - whereas the future is hard to foresee. But in the complex world we live in, even when limited to a special topic and discipline, there are innumerable variables and links between them. Nobody can overview them all and draw conclusions about covariance and causality. History has to be interpreted and it is easy to fall into the trap of rationalizing and streamlining the past. Here is my interpretation.
In the 1970s a new era of service research took off when a small number of individuals from Finland, Sweden, France, UK and the USA challenged the goods and manufacturing mainstream in management and especially in marketing. When I presented my $\mathrm{Ph}$ D dissertation on service in 1977 one professor told me: "You have looked into a very marginal area of economic life. To advance in academe you now have to do something more substantial and important." Christian Grönroos met similar reactions in Finland.

Despite opposition from certain academic circles, the number of service researchers soon grew into an international critical mass; in the 1980s the growth was exponential. Service research developed new knowledge about markets and the economy in general. The concept of the service encounter where suppliers and customers meet to produce and consume a service formed the basis for a more generalized view with relationship marketing, interaction and networks in the center. New information technology gradually began to influence how service was promoted, bought and performed.

The growth of service research during the 1980s and 1990s offered both empirical and conceptual developments. Personally I began to feel that service research locked itself up in a counterproductive paradigm and cultivated certain myths as rock-solid truths. I missed the excitement of the pioneering days and it made me feel uncomfortable. There was a dominance of certain themes, especially customer satisfaction and customer perceived quality using superficial statistical surveys as evidence. The mainstream dodged the demanding issues of the complexity of service systems and how they affected both markets and the welfare of society. The developments provided piles of fragments and partial models based on both armchair deduction and specific empirical studies. There was little syntheses on a higher level of abstraction and generality, i.e. grand theory. Service research had not found the core of service although many researchers touched on it from time to time. For example, the theory could not handle the dependency between goods and services. My own efforts to make a synthesis and develop higher level and general service theory were not as successful as I had wished.

Service research so far rested on several unsupported assertions and axioms. The Nordic School had questioned many of these and built up major service research centers such as CERS at Hanken (Finland) and CTF at Karlstad University (Sweden) and service research spread to many universities and smaller groups as well as to individual academics and consultants. Richard Normann (2001) spending much of his time in Sweden and Finland reconceptualized service thinking both through academia and consultancy. It is probably true that Finland and Sweden have the highest density of service researchers 
in the world. But service research emanating from business schools and business and management departments within universities has not spread to economics or to other social sciences like sociology and psychology. This lack of cross-fertilization is an alarming sign of low productivity of academic research and education.

In the early years of the new millennium a renewal of service appeared and instilled in me a new period of excitement. It was efficiently launched through two distinct approaches, S-D logic as a synthesis and the beginnings of a grand service theory; and the long term research program by IBM, Service Science, Management and Engineering (SSME) usually just referred as service science (Maglio \& Spohrer, 2010). They raised many of the issues from the Nordic School and other international research and conceptualized them further. As always in science there is not complete agreement about future developments, especially not in a transition period (Grönroos, 2011).

I have made a rough division of the recent history of service research in three periods (Gummesson, 2012):

- Paradigm 1 (pre-1970s). Services were not recognized; it was all about consumer goods and manufacturing.

- Paradigm 2 (1970s-2000s). An era of emphasizing goods/service differences; in rhetoric customer centric but it practical action supplier centric: do to the customer.

- Paradigm 3 (2000s-). An era of commonalities, interdependencies and a systemic, stakeholder centric approach addressing complex ecosystems with cocreation, resource integration, relationships, networks and interaction: do with others.

We are now establishing service in the Paradigm 3 era. A new logic of service broadened to embrace the whole of economic thinking is in the making. The transition is quick in some academic and practitioner circles but slow in others. Some try to have one foot in Paradigm 2 and one in Paradigm 3. They keep citing articles from the 1980s which are since long obsolete but were written by well-known professors. The articles once made a contribution but are now history. Unfortunately the reference system promoted by journals encourages authors to repeat the best-known references of the past, even when they are outdated. It means that the more an author has been cited the more he/she will be cited. The Reference List then becomes a Celebrity Name-Dropping List. If we had lived during the Scientific Revolution in the 1600s when it was eventually accepted that the world is not flat but round and is not the center of the universe, they would still have behaved as if the earth is flat and the center of the universe - but admitting that the earth had some rounded corners and was somewhat dependent on other planets. Unfortunately Paradigm 2 research and articles are still published in scientific journals. There is the Flat Earth Society for those who still believe the earth is flat; perhaps there is now need for a Flat Service Society.

A paradigm also includes the postulates of the research methodology-in-use. The best known methods paradigms are the positivist paradigm and the interpretivist paradigm. I introduce the complexity paradigm, appointing complexity to be the nucleus of social science research.

\section{METHODOLOGY: ELEVATING CASE STUDY RESEARCH TO CASE THEORY}

After my PhD dissertation I wrote a book about methodology, published in Swedish in 1985 and in 1991 by Sage in the US under the title Qualitative Methods in Management Research. It has since been revised and reprinted several times (Gummesson, 2000). I am both happy and surprised to note that despite the fact that the book has been around for several decades the citations grow at a progressively faster rate; in June 2014 they were over 3,200 (www.Harzing.com).

The interest in the book caused Sage to ask me to write a book on case study research. I had considerable experience of the method both as a consultant and scholar. My dissertation included 20 types of professional B2B services - management consultants, auditing firms, architects, business lawyers among them - and four cases of the actual buyingselling processes of professional service. I agreed to writing the book - but wasn't ready for it. It got a bit under way but in the process it became obvious that there was more to case study research than I had realized. But John Van Maanen of MIT encouraged me and Sage kept coming back on it. A couple of years ago I felt: It's now or never! Thank you, Delia Martinez-Alfonso for your patience and understanding! Eventually the book is now under publication (Gummesson, 2015).

During the past decades a large number of books on case study research have been published. I have some 25 of them and uncountable books and articles on qualitative research, quantitative research and the philosophy of science, and numerous articles and $\mathrm{PhD}$ theses of case study research applications, especially from the Nordic School. Together with my own experience the publications have been a great source of inspiration. I still felt that the method was not entirely understood and had an unexploited potential. The new developments had mainly come from general qualitative methodology, the improved access to data through the Internet and social media, and smarter software to classify, structure and retrieve qualitative data. The emergence of new - and controversial scientific paradigms such as interpretivism, post- 
modernism and critical theory have also added new dimensions to case study research.

The purpose of my new book is to elevate the status of case study research to where I think it belongs in science. During the writing of the book I found more to add and change than expected. I therefore saw it justified to put innovative in its title and gradually change the name of the methodology from case study research to case theory. The designation is analogous to other methodologies, for example grounded theory, practice theory, network theory and systems theory. In this sense the term theory covers both the process of knowledge generation and the outcome, the new knowledge.

The next sections offer a summary of characteristics of case theory. Some of them comply with the mainstream but others are new or are given more weight. In the book the new approach is motivated in more detail than this short paper can offer.

\subsection{The Complexity Paradigm and Interactive Research}

The first thing to do in research is to identify a topic or problem representing phenomena that you find interesting, set a purpose for your research and ask research questions. If you start with a research technique and for example take the statistical survey for granted as scientific and the natural choice and further take it for granted that statistical hypotheses testing will produce superior knowledge - and many business schools do - you have missed out. To be amenable to quantification data have to be stylized to make them easier to handle in equations (Kaldor, 1957). My conclusion is that they could equally well be called "distorted data". Social phenomena are complex but social scientists seem to shun complexity. In traditional positivist and quantitative research complexity is stylized by making non-linear phenomena linear and reducing a problem to an independent variable causing an effect on a dependent variable. In statistical surveys randomly selected respondents structure their answers in "yes/no/don't know" boxes or as points on scales. The data can be listed in tables and diagrams but also be further analyzed with advanced statistical techniques. In this way quantitative researchers claim that the research becomes objective, rigorous, generalizable, and that its reliability (replicability) can be measured. The survey technique is productive in situations where simple, straightforward answers are sufficient. It is taught as a generally applicable technique and has become grossly overused in business schools and organizations. It cannot address complexity and its validity and relevance is low.

Case theory can address complex issues with an unlimited number of variables and links - and that's what business and management is about. Although case study research is used to study phenomena which cannot be addressed through statistics or mathematics, dealing with complexity has rarely been put in the center as its most significant property. Instead cases study research is described as anecdotal, exploratory, conceptual, and a prelude to quantitative research.

Currently big data is launched as the future panacea of knowledge development. It claims that we now have so much data, that the data volume increases every nano-second and that computers can quickly combine data into meaningful patterns, i.e. generate theory. We do not have to worry about causality; covariance is enough to objectively and rigorously sort things out. I have heard similar prophecies throughout my professional career. The first was the PIMS project, Profit Impact of Marketing Strategy, which started in the mid-1960s. Grönroos and I interviewed key PIMS people at the Harvard-allied Strategic Planning Institute in the 1980s and I later met representatives in Sweden. PIMS may have raised awareness of the elusiveness of marketing issues but its legacy is poor despite the enormous resources that were put into it. One of the lessons we should have learnt by now is the weaknesses of quantitative research when trying to establish simple solutions to complex issues without really addressing the complexity. What big data will create in the future I don't know; I am not that software sophisticated. I have learnt to be careful with making predictions so let me keep an open mind. Waiting for a big data paradigm shift in science I will stick to upgrading case study research to case theory.

By digging into complexity the core of a phenomenon can be found and valid and relevant theory based on real world data can be designed. This requires close access to data which in turn opens up for a series of data generating techniques of which informal interviews, focus groups and observations are the most frequently used. Still these are often too detached from the object of study to offer high quality data. I have therefore since long advocated management action research as a designation for involved research where the researcher has the dual role of researcher and actor. In contrast to the conventional requisite that the researcher should be detached, I emphasize the need for interactive research: interaction with data, with respondents, between your inner and outer self, and so on.

\subsection{Knowledge as Pragmatic Wisdom}

The purpose of doing systematic research is to acquire more and better knowledge. Knowledge remains a major philosophical issue since millennia. It is a fuzzy concept and perhaps we will never quite grasp it. But today we claim that we live in the knowledge society, the employee is a knowledge worker, and knowledge is the major economic resource.

My knowledge concept includes two interdependent types: 
- Explicit knowledge which can be communicated to others through words, numbers, graphs and software. It is open to be assessed by others and therefore be intersubjectively, sometimes even objectively, verified. It is the hallmark of mainstream positivist science but it has severe limitations.

- Tacit knowledge which cannot be openly communicated (at least not yet) but can be learnt though participation and practice. Tacit knowledge includes common sense, experience, intuition, sound judgment, insights, wisdom, instinct, hunches, gut feeling - there are lots of words that attempt to pinpoint this wordless rascal. It is not accepted in mainstream science but is present whether you like it or not. Launched by Polanyi (1966) tacit knowledge has been tied to business by Nonaka and Takeuchi (1995) who show how Japanese companies use it and work systematically to make it explicit.

My thesis is that genuine knowledge grows from an iterative and interactive process between the two types and I put equal weight on them. This may disturb positivists, but I cannot see that explicit knowledge alone can help us advance the frontiers of knowledge. Some of the tacit knowledge may become explicit but some will not. As a researcher you should be true to yourself and the world, trying to look at yourself both from the outside - extrospection - and the inside - introspection - where you find your tacit knowledge. You need to be a reflective researcher and not just an administrator of a certain research technique. Furthermore, in business and management your theory needs to be applicable in practice.

We have to accept that reality in fuzzy and ambiguous. Therefore concepts and categories are fuzzy sets, meaning that they have a core from which the meaning fades away gradually and overlaps with other concepts and categories. By stylizing everything to fit square boxes with clear boundaries (crisp sets) we take out a substantial portion of reality. The words pragmatic and practical have the same roots, both referring to getting things done. I use the concept pragmatic wisdom for what can be transformed into decisions, actions and results. It has a wider meaning that just knowledge and in case theory it is the most developed form of knowledge.

\subsection{The Purposes of Case Theory: Particularization, Generalization and Theory Generation} interrelated:

Case theory has two purposes which can also be

- Particularization. We can study a particular case for example to help an organization solve a current problem or develop a specific area, such as its accounting system. This is the market for consultants. There can also be a specific interest in a company like how Steve Jobs made Apple come up with breakthrough innovations and during his last years made Apple the highest valued company on the stock exchange.

- Generalization. It is routinely claimed that results from case studies cannot be generalized. I disagree. It is a misunderstanding peddled by quantitative researchers that all gneralization is statyistical The bulk of research in business and management results in fragments and their relationships to other knowledge are not established. We need more general theory that is grounded in the real world and not based on preconceived theory and highly stylized data. A single case can generate substantive theory meant to better understand a specific situation. This theory can be applied to cases which are similar to the original case. It can also be the start for a row of cases and theory generation toward generalization to mid-range and grand theory. It is analytic generalization concerned with understanding How? Who? and Why? A widespread misunderstanding is that generalization is always statistical answering questions of quantity: How much? How often? and How many?

Mid-range theory should be pragmatic and be used until something better comes up; it has also been called currently useful generalizations. It consists of models, checklists and heuristics. Both consultants and scholars have made themselves known for such theory. In business strategy some of the most wide-spread are the SWOT analysis combining strengths and weaknesses with opportunities and threats; the Boston Matrix, best known for identifying "cash cows"; and Michael Porter's value chain and five forces of competition. The academic researcher has a scholarly responsibility to offer theory that is actionable. The problem arises when for example it was disovered that the value chain and the five forces were indequate and Porter's consulting company went bankrupt in 2012. not well-rooted in today's reality. In marketing the $4 P s$ - product, price, promotion and place - have been carved in stone and after half a century still dominate marketing textbooks although their practical relevance is not supported by new general theory.

The categories substantive theory, mid-range theory and grand theory are seen as fuzzy sets thus forming three partly overlapping theory zones stretching from the concrete and specific to the abstract and general. Mid-range theory has three main sources which are often combined: experience and other tacit knowledge, explicit research from specific cases, and 
grand theory from the zone of high abstraction. Grand theory, which has found the core of a phenomenon, should be able to send back simplifications to the midrange zone where it is made implementable in practice. As these simplifications have gone all the way from substantive data and up to conceptualization and integration of data fragments into grand theory they are a contribution to pragmatic wisdom.

Case theory thus makes it possible to contribute to the development of better theory. It further makes it possible to test theory through constant comparison between extant and new theory. Theory testing is usually taken from quantitative and positivist theory demanding that hypotheses are set up and tested on random samples. I do not subscribe to this as a panacea. If case research comes up with new knowledge, the new theory could be compared to the reigning theory and if found better it should replace it. The transition to the new should not be held back by elaborate, quantitative, costly and time-consuming tests of the old. If a better theory is found - like the theory found in Paradigm 3 is better than theory from Paradigm 2 - we should leave Paradigm 2 to historians. Pragmatic wisdom in business and management is about the present and the future and not about the past.

Theory develops both from incremental improvements of current theory and the discovery of new theory. All this refers to new knowledge innovation - which is the current buzzword in business and management research.

\subsection{From Thick and Rich Descriptions to Scientific Narratives}

In the core of case study research is the case narrative, which is perceived to be a primarily verbal description although it can include quantitative and graphic elements. It is often presented as an objective description of data and fact of an organization, an event, a process, etc. free from analysis, interpretation and value judgments. But you can't make such a description even if you want to. Any description requires the writer to make choices about what to include and to find the "right" words and structures. Therefore a description is also the beginnings of analysis and interpretation. Further, thick or rich description is recommended - but watch out! A thick report only becomes rich if the data has relevance to the research questions. So thick and rich are not about a maximum but about an optimum or in practice about what we have to accept as satisficing.

The real scientific contribution of a narrative is the conceptualization of the case. It is primarily verbal which is a limitation. For that reason I have extended case theory to include two languages which can deal with complexity in amore systematic and structured way. These are network theory and systems theory. They offer the languages of links and nodes and various types of components and systems. The two theories can be used on different levels of sophistication. You can use them in a discussion and proceed with graphic paper-and-pencil sketches to make the discussion more structured and clear. Eventually you may be able to assign numbers and make statistical and mathematical computer simulations.

There are no shortcuts. If you start out with quantifications and simulations without having founded the issue on explicit empirical data, your best tacit knowledge and theory generation you fall into the trap of techniques over useful results. Today very few social issues go all the way from the basics to the most sophisticated techniques. A major reason is limited knowledge among researchers and time and other resource restrictions. By extending the case narrative beyond the verbal with an effort to be more systematic, the case narrative can be given a higher scientific status and deserve the designation of scientific narrative.

Context, the Persona Factor and Researchscapes

The research context for business and management disciplines is business enterprises, governments and non-government organizations, and households (consumers and citizens). Methodology books claim that social science methodology is generally applicable. It is only half true; some of its elements can be shared but others have to adapt to the context where they are applied. In case theory I stress context dependency.

First, there is the context of the domain for our research. It is presented in a conceptual language, especially so in quantitative research, whereas in reality the specific personalities that act in the context should also be considered. This is referred to as the persona factor. Second, I also stress the persona of the individual researchers and the group of researchers and research systems to which they belong, the persona of researchscape. This means recognition of subjectivity, discredited in mainstream research but very much present in real life. The famous sociologist Robert Merton Sr. wrote about the sociology of science in the 1950s and laid bare that research had a social side and not just an objective, detached side. The persona factor exerts considerable influence on how research is performed.

\subsection{Quantitative and Qualitative Research: The Terrorism of Received Categories}

Numerous categories have established themselves since decades and centuries and are routinely applied in academic research. Many of them are irrelevant and outdated. They terrorize our minds and researchscapes and detract us from what is important. They give rise to pseudo-research.

Case study research is routinely classified as qualitative and second to quantitative research. I want to dissolve this categorization; it does not contribute to the quality and productivity of research. It creates self- 
imposed restrictions and a focus on methodological ritual over relevant results. It does $f$ not contribute to pragmatic wisdom. Quantitative and qualitative are just two languages: the numbers language and the words language. The numbers language flatters itself of being rigorous, objective, scientific, generalizable and offering reliability and validity. Chose any great attribute you can find and quantitative research has it! Qualitative research on the other hand is characterized as a conceptual and explorative pilot stage to doing the real thing which means going empirical (read: quantitative) and formulate and test hypotheses.

In communications theory it is known that the spoken and written language only accounts for the minor part of communication between people while "body-language" accounts for the major part. Still we limit the vast majority of academic research to words and numbers. Quantitative and qualitative are just two of many properties of research but not the overriding ones. When you take a close look at quantitative research and even if it deploys sophisticated statistical techniques like factor analysis and structural equations, you can list dozens of objections: they are dependent on subjectivity, facilitating assumptions, stylized data, and judgment calls but the researchers do not stress these shortcomings or may not even be aware of their influence.

Among other phenomena that do not deserve a place as overriding categories are goods and services; the service sector, the manufacturing sector and the agricultural sector; supplier and customer; socials science, natural science and the humanities; high tech and high touch; online and offline; analogue and digital; and global and local. They are just some among numerous dimensions that can be used to characterize business and management. But these terror categories are used by the mainstream service research. Quantitative positivist and deductive research uphold them and let them form the starting point for research. They are rooted in Paradigm 1 and 2. In Paradigm 3 of service and management research many of them are abandoned and have found a place on the level where they belong. There is more to do and who knows, maybe there is a Paradigm 4 lurking around the corner.

\subsection{Additional Case Theory Tenets in Brief}

The following tenets are equally important as those discussed so far and will need further explanation. Considering the space of a short chapter they are only mentioned here to make the reader aware of their existence as part of case theory:

- Reduction of data is recommended in the methods literature. Instead it should be condensation of data, making data more comprehensive and dense without losing in content.
- Analysis and interpretation. Analysis is the effort to break down a situation into wellstructured categories and concepts using operational definitions and constructs. Interpretation is a merger of explicit and tacit knowledge. Analysis should always work hand in hand with interpretation.

- From either/or to both/and. Western science lives in an either/or world instead of accepting the both/and of reality. I avoid talking about opposites and consider phenomena interdependent and complementary. This thinking is a natural part of Eastern philosophy.

- Validity and relevance. The validity of the outcome of research and its relevance-in-use are more important than the positivist reliability and rigor of the research process.

- Single, multiple or embedded cases. Cases are usually classified as single, multiple or embedded (nested). To me this is less important. A single case is often followed by more cases to reach saturation of data unless the purpose is limited to a particular case. Multiple cases can be anything from two to hundreds or even thousands and there is no standard rule for the number; it's always contingent on what you are studying and why. In the light of systems and network theory all cases are embedded which makes the category redundant. What else could cases be? Standalones with no connection to the rest of world? "No man is an island, entire of itself", as the English poet, priest and lawyer John Donne wrote 400 years ago.

- Inductive, deductive, abductive. Inductive research starts with real world data from interviews, observations and other sources without using any preconceived theory. Train yourself to be a blank sheet as much as you can and let reality emerge. Deductive research starts with extant theory and reality is forced into its format. The initial inductive research is followed by deductive phases and data is organized in concepts and categories. This combination is sometimes referred to abductive research. But the starting point constitutes the critical difference between inductive and deductive research.

- Temporal aspects. It is often claimed that case studies are about contemporary phenomena but I see no time restrictions. Case theory can encompass ongoing processes (the present), be reconstructive (the past) or be predictive (the future). The time dimensions are interlinked but all offer specific challenges and all are afflicted by uncertainty. Being part of an ongoing process is sometimes straightforward but often we cannot grasp its 
complexity. We may think we can find out what happened in the past but in the complex social settings of companies, governments and markets it is difficult to sort out the essentials and to get access to pertinent data. The past and the current connect with tomorrow and we start making predictions. Although there is a classic requirement that good theory should have predictive capacity, predictions remain guesses unless there is a stable, repetitive pattern like the number of kids born in a year determines the need for schools some years later. If the future is affected by discontinuities, like the new infrastructure offered by the Internet, mobile communication and social media, there is no established pattern.

\section{AN ILLUSTRATION TO CASE THEORY}

To help make case theory more tangible for the reader I present an example from a recent Nordic School PhD thesis presented at the University of Tampere, Finland (Närvänen, 2013; Närvänen et al., 2014). This illustration does not cover all case theory aspects but it hopefully gives a fair idea about what case theory is.

The case is Reino \& Aino (R\&A), a Finnish manufacturer of slippers. The product was traditional grandpa and grandma slippers but sales were fading. R\&A was taken over by new owners in 2005 . From 50,000 pairs sold then, sales had risen to over 500,000 in 2010. The slippers became a lifestyle product for all ages. Close business-to-customer and customer-tobusiness (B2C/C2B) cocreation and local events organized through customer-to-customer (C2C) interaction made this happen, keeping the marketing budget low.

The purpose of studying the case was to extend the understanding of collective consumption of brands by finding and categorizing heterogeneous consumption communities based on inductively generated real world data. It is a theory generating approach, which considers the complexity of real markets. Data was generated through over 30 in-depth and informal personal interviews, observation and participation in two R\&A events during altogether six days generating 54 pages of field notes and 300 photos taken by the researcher. In addition offline and online documents were studied, among them photos, advertisements, blogs, Facebook and fan group interaction. Analysis and interpretation, although partially simultaneous with data generation, was performed through constant comparison between the specific data of the case and extant literature and theory.

The thesis is based on a single case and is primarily guided by practice theory where the actual practices, habits and routines of consumers are studied (see also Helkkula et al., 2012). When it was written I had not yet introduced case theory but many of its elements have been discussed in my articles during the past ten years and are found in the thesis. For example, the complexity of communities is recognized and is seen as networks of people; mixed methods for data generation and analysis are used; efforts are made to secure access to high quality empirical data; and the single case is the empirical base for generating theory in both the substantive, mid-range and grand theory zones. And Paradigm 3 is underpinning the study. The slippers are not treated as goods but as part of service and value-in-use. It shows that all economic activity is based on cocreation and resource sharing involving relationships between numerous stakeholders; it is not just a supplier doing something to a consumer.

In the spirit of case theory a single case is always embedded in networks and systems. The single case offers an opportunity to inductively go deep into an issue. The R\&A case became the kick-off for a journey through extant classifications of consumer communities and collectives. Through constant comparison with them and the data from R\&A the heterogeneity and complexity of collective consumption stood out and generated a new way of categorizing consumer collectives. The outcome was a theory going beyond the single case and can be used as a starting point for other case studies to strive in the direction of both practical mid-range theory and general, grand theory. It is not a matter of testing hypotheses but of doing further cases based on purposeful sampling toward saturation.

\section{CONCLUSIONS}

My advocacy for case theory is an effort to propel service research as well as other research in economic sciences in the direction of more realism. We need to address the complexity of management, business and economics, generate grand theory and from that derive the necessary simplicity needed to make decisions, implement them and achieve results. Case theory can offer higher validity and relevance by focusing on outcome instead of on details of the research process and techniques to augment reliability and rigor. By accepting the tenets of fuzzy set theory from mathematics it is only natural to let explicit and tacit knowledge join forces to develop pragmatic wisdom.

I do not live under the illusion that case theory is the final answer - understanding what knowledge is has been on the philosophers' agenda for thousands of years and still is - but I hope it can make researchers aware of the need to advance research methodology and stimulate them to make their own contributions. It is also an urge to positivist researchers to see the limitations of quantitative research and stop claiming 
that the numbers language is a generally valid highway to scientific excellence.

\section{REFERENCES}

Grönroos, C. (2011). Value co-creation in service logic: a critical analysis. Marketing Theory, 11 (3), 279-301.

Gummesson, E. (2000). Qualitative methods in management research. Thousand Oaks, CA: Sage.

Gummesson, E. (2012). The three service marketing paradigms: Which one are you guided by? Mercati e Competitività, 1, 5-13 (Italy).

Gummesson, E. (2015). Innovative case study research in business and management. London: Sage.

Helkkula, A., Kelleher, C. and Voima, P. (2012). Practices and experiences: Challenges and opportunities for value research. Journal of Service Management, 23 (4), 554-570.

Kaldor, N. (1957). A model of economic growth. The Economic Journal, 67 (268), 591-624.
Lusch, R. F. and Vargo, S. L. (2014). Service-dominant logic. Cambridge, UK: Cambridge University Press.

Maglio, P. P. and Spohrer, J. C. (2010). Toward a science of service systems. In P. P. Maglio, C. A. Kieliszewski and J. C. Spohrer (Eds.), Handbook of service science. New York: Springer.

Närvänen, E. (2013). Extending the collective consumption of brands. Tampere, Finland: Tampere University Press.

Närvänen, E., Gummesson, E. and Kuusela, H. (2014). The Collective Consumption Network. Managing Service Quality, 24 (6).

Normann, R. (2001). Reframing business. Chichester, UK: Wiley.

Polanyi, M. (1966). The tacit dimension. Chicago, IL: University of Chicago Press.

Nonaka, I. and Takeuchi, H. (1995). The knowledge creating company. New York: Oxford University Press. 